Journal of Information Technology and Digital World (2020)

Vol.02/ No. 01

Pages: 43-52

https://www.irojournals.com/itdw/

DOI: https://doi.org/10.36548/jitdw.2020.1.004

\title{
Metaheuristics Optimizations for Speed Regulation in Self Driving Vehicles
}

\author{
A. Sathesh, \\ Department of EEE, \\ Eritrea Institute of Technology, \\ Eritrea. \\ Email: sathesh4you@gmail.com
}

\begin{abstract}
The speed regulation becomes an important necessity in the self -driving vehicles that are engaged in various driving chores. It prevails as a prominent area of research from the past decades, proportional, integral and the derivative controllers play significant role in regulating the movement velocity of the vehicles as perfect adjustments of the parameters linked with the controller could afford to provide a proper speed regulation. But the attaining a perfect adjustments in the parameters are highly tedious. To attain a proper speed regulation in the self-driving vehicles, the paper attempts to utilize the metaheuristics algorithms for optimizing the parameters and minimizing the errors associated with its attributes. A regulating function to fine tune the proportional derivative and the integral controller parameters is formulated in the proffered method and the proper adjustment is achieved utilizing the heuristic optimization. Triple algorithms, genetic (Ge-Al), memetics (Me-Al) and adaptive direct search based on mesh (M-ADS) is used in the proffered method to carry out the optimizations. The results on applying the proposed optimization techniques proves to be more accurate compared to the conventional optimization techniques that were employed in adjusting the absolute error that is integral and the minimizing oscillatory performances and the performance index.
\end{abstract}

Keywords: Self-Driving Vehicles, Metaheuristic Algorithms, Speed Regulation, Attribute Adjustment, PID Controller

\section{Introduction}

Regulating the speed of the self-driving vehicle is automatically handled by the inner component that controls the movement of the vehicle. So far the issues on the regulating the movement of the vehicles was managed by the conventional proportional integral and derivative controller and the $\mathrm{Ge}-\mathrm{Al}$ apart from this many other control methodologies following adaptive techniques to control the vehicle movement and the artificial intelligence based controlling was also devised. All the methods aimed to achieve the same objective the optimization of the parameters.

Though the aim of the preceding papers and the proffered method is similar and attempts to adjust the parameters. The proffered method differed from the prevailing as the prevailing methods aimed in adjusting the set points with cost functions based on the integral errors and the proffered methods attempts in

ISSN: 2582-418X (online)

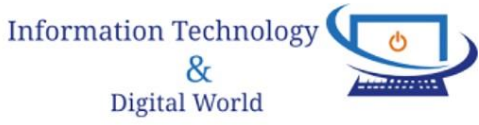


Journal of Information Technology and Digital World (2020)

Vol.02/ No. 01

Pages: 43-52

https://www.irojournals.com/itdw/

DOI: https://doi.org/10.36548/jitdw.2020.1.004

optimizing the gain of the PID controller using the metaheuristics optimization with the performance index "integral squared errors, integral absolute errors, integral time absolute error and the integral time squared errors" as the cost function resulting in continuously changing performances in the signals used in controlling and as well as the outcome of the system.

The proportional integral derivative regulator is basic mechanism to control the operation in the feedback system with the closed loop, it is highly utilized in the industries for controlling the system operations. The PID accepts the miscalculations of the expected output subtracted from the attained outcome and its outcome is fed as input to the system that needs to be regulated. The regulator mainly aims in minimizing the error by tuning the input of the system.

\subsection{PID Proportional- Integral- Derivative Controller}

A PID controller is estimated by its triple components: proportional, integral and the derivative that greatly impacts the attributes of the output. However identifying the set up for the PID with the capability to minimize the error, over-oscillation and the settling time to 'zero' is impractical. So the main objective is to fine tune the parameters of the PID according to the applications demand and to have a compensation across the same. The 'anti-wind up component' guarantees the maintenance of the signal for controlling along its limits of actuation.

The response of the proportional component lays as the fundamental for all the triple components that estimate the performance of the PID, the rest of the components integral and the derivative if present are incorporated with the response of the proportional component. The rate of variations in the measurement that appears as the oscillations in the outcome is meant as proportional.

The product is termed as the 'gain' of the regulator, in many case the action of the proportional component is tuned by adjusting the gain, whereas some cases relies on the adjustment of the proportional bands. However the effects seems to be the same. The equation 1 is framed in this regard.

$$
\operatorname{Pro}(t+1)=\operatorname{Tpor}_{\text {Gain }} * \operatorname{Sub}(t)+B
$$

Where Pro $=$ proportional, Tpor $_{\text {Gain }}=$ "proportional gain that is tunable", $S u b(t)=$ "difference between the outcome of the plant, and the set point" $B=$ Bias or reset which is set 'zero' for simplifying. The outcomes that are proportional to the integral error is given by the integral movements. This eludes the

ISSN: 2582-418X (online) 
Journal of Information Technology and Digital World (2020)

Vol.02/ No. 01

Pages: 43-52

https://www.irojournals.com/itdw/

DOI: https://doi.org/10.36548/jitdw.2020.1.004

steady state errors that are caused by the mode 'proportional'. But attains an elongated time for establishing, with the slow responses and long duration of oscillations compared to the 'proportional action'. The integral movement is estimated according to the equation 2

$$
\operatorname{In}(t+1)=\operatorname{In}(t)+\left(\text { Tpor }_{\text {Gain }} * S p / \operatorname{In}_{\text {gain }}\right) \operatorname{Sub}(t)
$$

Where $I n=$ integral component value, $I n_{\text {gain }}=$ Integral gain, $S p=$ Sampling Period, the precise duration taken to regulate proportional movement is termed as the integral gain. The derivative movement is expressed as in the equation 3 .

$$
D e(t+1)=\frac{D e_{\text {gain }}}{D e_{\text {gain }}+F_{n} * S p} * D e(t)-\frac{\text { ppor }_{\text {Gain }} * \operatorname{De}_{\text {gain }} * F_{n}}{D e_{\text {gain }}+F_{n} * S p}\left(y_{t}-y_{(t-1)}\right)
$$

Where $D e=$ derivative movement, $F_{n}=$ filter for noise. The proposed method aims in optimizing the gains of all the three components with the integral errors as the cost functions. The proffered method is organized with the section 2 detailing the related works, section 3 explaining he system model and the section 4 the optimization using the metaheuristics, section 5 presenting the analysis of the application of the proposed method and section 6 providing the concluding part.

\section{Related Works}

Moscato et al [1] proposes the "On evolution, search, optimization, genetic algorithms and martial arts: Towards memetic algorithms." Killingsworth, N., et al [2] performed the "PID tuning using extremum seeking. No. UCRL-JRNL-217161" Audet et al [3] conducted the "Mesh adaptive direct search algorithms for constrained optimization."

Smys, S et al [4] proposed the. "Autonomous Vehicle Navigation in Communication Challenged Environments in a Simulation Approach." Ghaheri et al [5] conducted the "The applications of genetic algorithms in medicine." Rout, M. K et al [6] presented the "PID controller design for cruise control system using genetic algorithm." Ribeiro et al [7] performed the "Comparison of PID controller tuning methods: analytical/classical techniques versus optimization algorithms."

ISSN: 2582-418X (online) 
Journal of Information Technology and Digital World (2020)

Vol.02/ No. 01

Pages: 43-52

https://www.irojournals.com/itdw/

DOI: https://doi.org/10.36548/jitdw.2020.1.004

Metawa, et al [8] presented the "Genetic algorithm based model for optimizing bank lending decisions." Aparicio et al [9] conducted the "Development and use of vehicle dynamics simulation software as support for road vehicles theory teaching." G. Ranganathan et al [10] put forth the "Robot assisted sensing, control and manufacture in automobile industry."

Ramesh, S et al [11] devised the. "A software-based heuristic clustered (sbhc) architecture for the performance improvement in manet." Manoharan et al [12] developed an. "An Improved Safety Algorithm for Artificial Intelligence Enabled Processors in Self Driving Cars."

\section{System Model}

The speed regulation in the self-driving vehicle is usually attained by regulating the movements of the throttle pedal, so to optimize the parameters and the adjust the movement of the controller the proffered method utilizes only two fundamental forces, the two major forces are the "tractive force and the rolling resistance" the former enables the vehicle to move forward and the latter opposes the force applied. The equation 4 is formed in this regard.

$$
\begin{aligned}
& \text { Tractive Force }=\text { maximum accelaration } * \text { Vehicle Weight } \\
& \text { Rolling Resistance }=\text { Rate of Friction } * \text { Vehicle Weight }
\end{aligned}
$$

Where the acceleration $=\left(\right.$ Tpor $_{\text {Gain }}-$ Rolling Resistance $) /$ Vehicle Weight and the velocity at the time period $(\mathrm{t}+1)$ is given as the product of set points which is 0 or 1 , and acceleration with respect to time, and summed up with the velocity of the vehicle at time ' $t$ ' the diagram below shows the system model that has to be regulated.

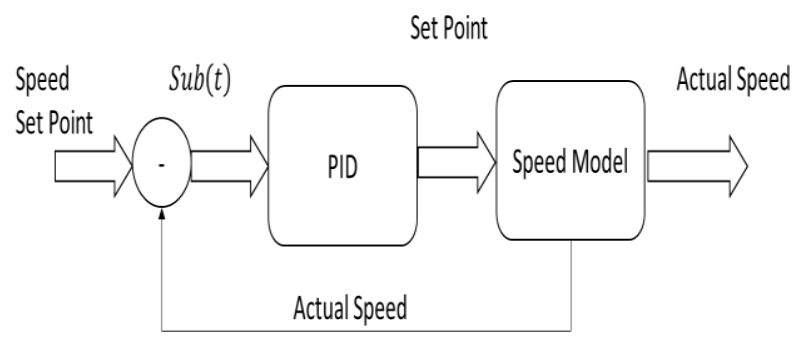

Figure.1 System Model to be Regulated

ISSN: 2582-418X (online) 
Journal of Information Technology and Digital World (2020)

Vol.02/ No. 01

Pages: 43-52

https://www.irojournals.com/itdw/

DOI: https://doi.org/10.36548/jitdw.2020.1.004

The estimation of errors in the PID regulator is listed below, the miscalculations performed by the PID are estimated considering four parameters, according to the outcomes observed. The first one is the over shot $\left(O v_{S h}\right)$, it is the ratio across the outcome of the regulator w.r.t steady state value of the set point, on reaching the reference value. The next is the duration taken in attaining the stable signal value and this is known as the settling time, the next is the steady state error, decay ratio and global error function. Etc.

\section{Optimization Using the Metaheuristics}

The optimization methods are used to identify the lower as well as the higher variable among various variables that are present with the certain restrictions imposed. For a well-known structure the methods such as gradient descent and the simplex is used. Whereas for a structure that is unknown the black-box method is used. The metaheuristics put forth is the 'black box method' the optimization of the speed in selfdriving vehicle is achieved using the three metaheuristics, even without in depth description of the vehicle model. The gain parameters of the PID are optimized using the three methods the tabulation.1below summarizes the procedure of the three metaheuristics used in the optimization.

\begin{tabular}{|c|c|c|}
\hline Genetic Algorithm & Memetic Algorithm & $\begin{array}{l}\text { Mesh Adaptive direct search } \\
\text { Algorithm }\end{array}$ \\
\hline 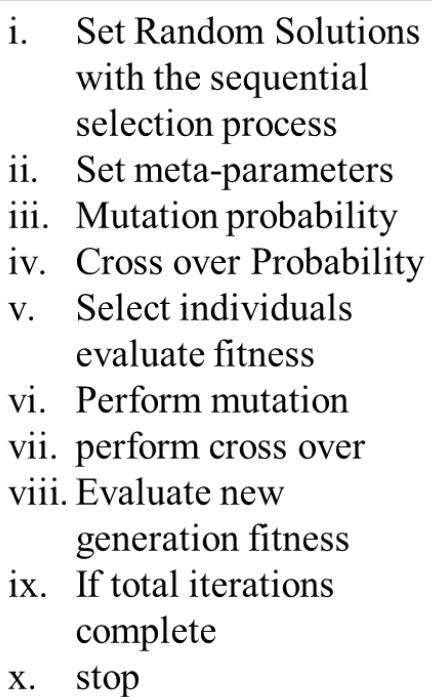 & $\begin{array}{ll}\text { i. } & \text { Set Random solutions } \\
\text { ii. } & \text { Select individuals } \\
\text { iii. } & \text { Perform mutation } \\
\text { iv. } & \text { Perform cross over } \\
\text { v. } & \text { Local optimization is } \\
& \text { done with gradient } \\
& \text { descent using the } \\
& \text { Resilient Back } \\
& \text { propagation }\end{array}$ & 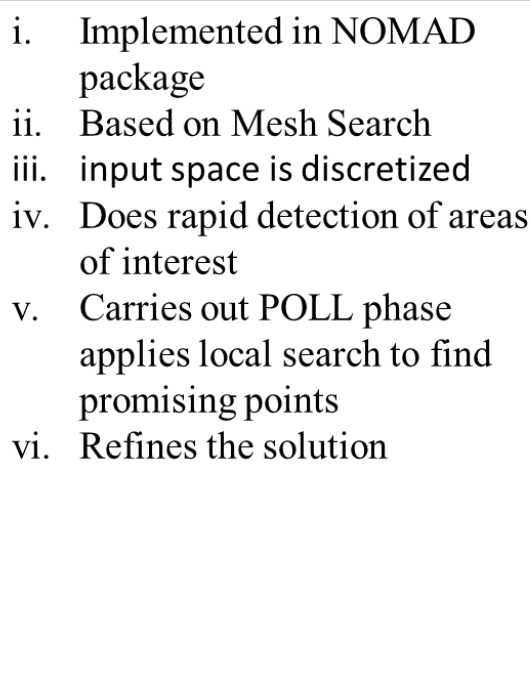 \\
\hline
\end{tabular}

Table.1 Procedures of Metaheuristic Operations

ISSN: 2582-418X (online) 
Journal of Information Technology and Digital World (2020)

Vol.02/ No. 01

Pages: 43-52

https://www.irojournals.com/itdw/

DOI: https://doi.org/10.36548/jitdw.2020.1.004

The values of the gain are maintained in similar range by estimating the fitness ' $F$ ', so the fitness is determined as shown in equation. 5

$$
F=\sum_{\text {desination }} 1 / 1+\text { error }_{\text {destination }}
$$

\section{Performance Analysis}

The optimization process for regulating the speed in the self-driving vehicle, is carried out in two strides first conducting the optimization and then performing the analyses by examining the controllers optimized in a cross validation strategy. For every optimization procedure, the optimization is done using the initial set point sequence of step response that is generated randomly and then simultaneously the error is determined with the second set of step response. The table. 2 below shows the component used in the process.

\begin{tabular}{|l|l|}
\hline \multicolumn{1}{|c|}{ Parameters } & \multicolumn{1}{c|}{ Values } \\
\hline Vehicle Model & Self Driving \\
\hline Set point & 2 \\
\hline No . of. Iterations & 500 \\
\hline Settling Time & $<0.0002 \mathrm{~s}$ \\
\hline Closed Loops & 400 \\
\hline Algorithms used & Ge-Al, Me-Al,M-ADS \\
\hline Mutation probability & .3 \\
\hline Cross over probability & .7 \\
\hline Population & 100 \\
\hline
\end{tabular}

Table.2 Parameter s Utilized

The figure. 2 below shows the accuracy of results obtained by the three algorithms, the result observed is compared with the classical optimization methods that usually optimizes the integral absolute error.

ISSN: 2582-418X (online) 
Journal of Information Technology and Digital World (2020)

Vol.02/ No. 01

Pages: 43-52

https://www.irojournals.com/itdw/

DOI: https://doi.org/10.36548/jitdw.2020.1.004

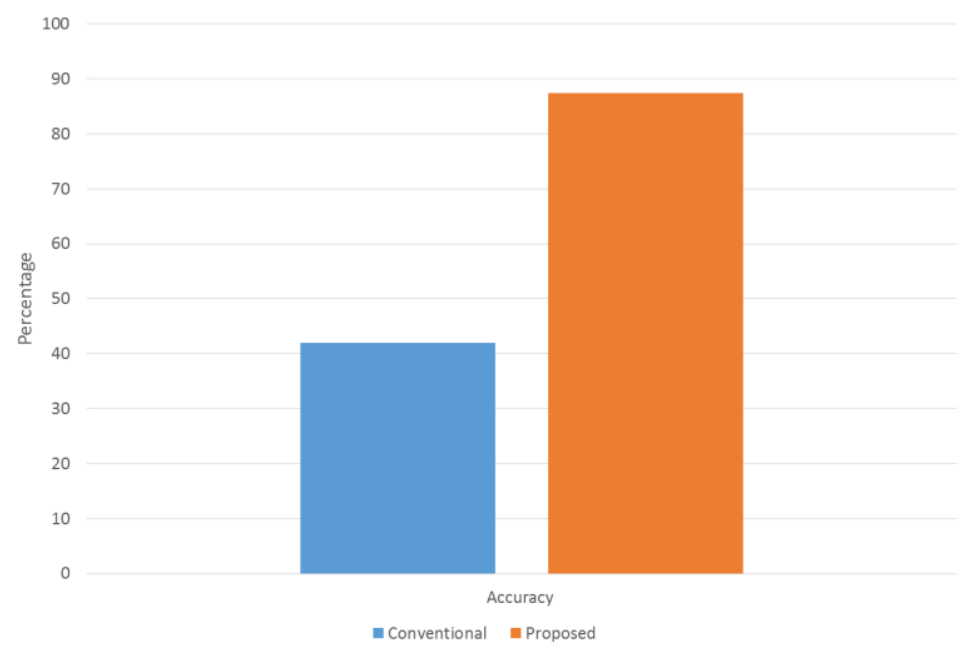

Figure.2 Accuracy Observed

The table. 3 below presents the error comparison of the three metaheuristics selected. The details of the gain parameters obtained, in the triple components of PID, the decay ratio, over shoot, settling time, steady state error and the global error are also included to the table. 3

\begin{tabular}{|l|l|l|l|l|l|l|l|l|l|}
\hline Algorithms & $\begin{array}{c}\text { Proportional } \\
\text { gain }\end{array}$ & $\begin{array}{c}\text { Integral } \\
\text { gain }\end{array}$ & $\begin{array}{c}\text { Derivative } \\
\text { gain }\end{array}$ & $\begin{array}{c}\text { Error in } \\
\text { optimization } \\
\text { process }\end{array}$ & $\begin{array}{c}\text { Error in } \\
\text { Cross } \\
\text { Validation }\end{array}$ & $\begin{array}{c}\text { Settling } \\
\text { time }\end{array}$ & Over shoot & Decay ratio & $\begin{array}{c}\text { Steady } \\
\text { state error }\end{array}$ \\
\hline $\mathrm{Ge}-\mathrm{Al}$ & .082 & .01 & 2 & 2 & 3 & .19 & .26 & 4.8 & 2 \\
\hline $\mathrm{Me}-\mathrm{Al}$ & .084 & .01 & 2 & 2 & 3 & .18 & .24 & 6 & 2 \\
\hline $\mathrm{M}-\mathrm{ADS}$ & .059 & .01 & 3 & 2 & 3 & .17 & 1.2 & 4 & 2 \\
\hline $\begin{array}{l}\text { Convention } \\
\text { al }\end{array}$ & .524 & .0001 & 2.5 & 15.56 & 15 & .5 & 1.34 & 115 & .8 \\
\hline
\end{tabular}

Table.3 Error Comparison

Further the robustness of the proposed method is examined by evaluating the signal conflicts that have occurred. The results observed for the robust analyses are based on the "signal disturbance test results" are represented in the figure. 3 below.

ISSN: 2582-418X (online) 
Journal of Information Technology and Digital World (2020)

Vol.02/ No. 01

Pages: 43-52

https://www.irojournals.com/itdw/

DOI: https://doi.org/10.36548/jitdw.2020.1.004

$\boldsymbol{\square}$ Steady state value in $(\mathrm{KM} / \mathrm{H}) \quad \square$ Over shoot $(\mathrm{KM} / \mathrm{h}) \quad$ Decay Ratio $\square$ Settling Time $\mathbf{u}$ Cross validation error

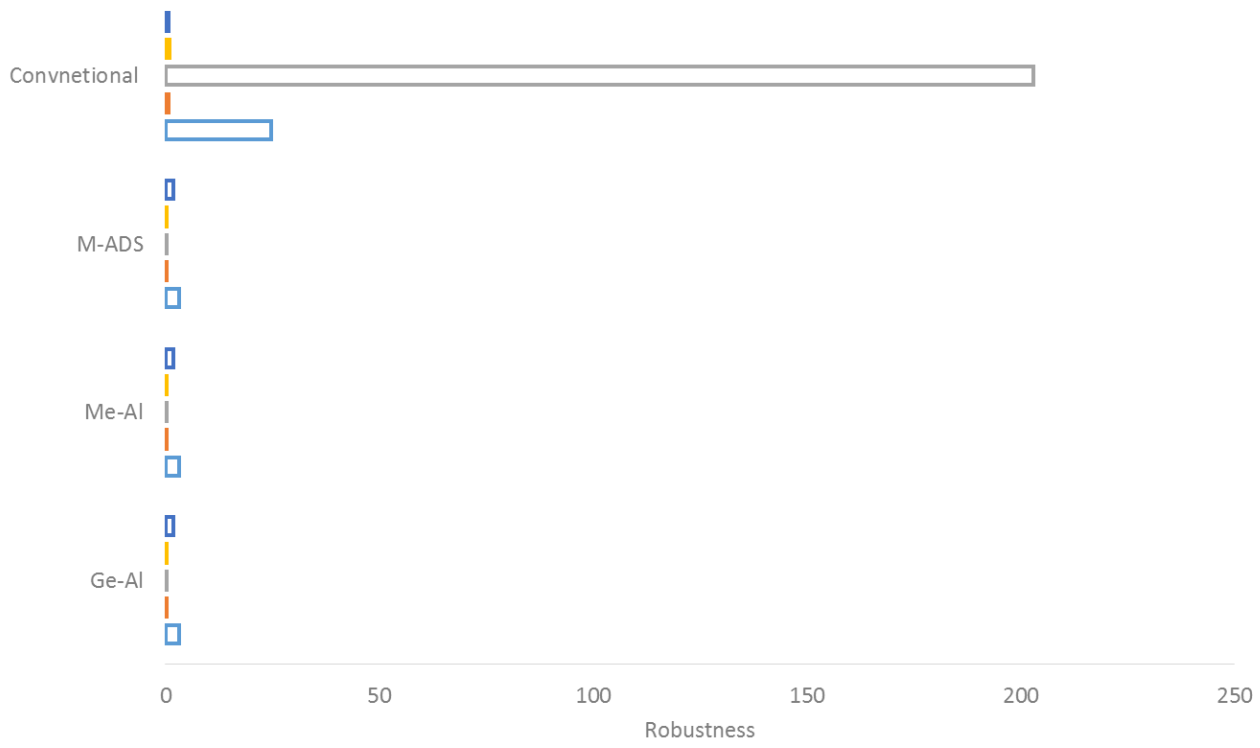

Figure.3 Robustness

The robustness is determined for the conflicts caused in the signal used as references as a random noise of $.1 \%$, this is acquired from the maximum error specification of the speed sensor in the vehicle. Further the figure. 4 below shows the performance analysis of the three algorithms in terms of resulting speed value from the results obtained it was noted that lower the value of the global error function better would be the performance among the three the $\mathrm{Me}-\mathrm{Al}$ proves to have a better performance over the $\mathrm{Ge}-\mathrm{Al}$ and the $\mathrm{M}$ ADS, but the alignment of the all the methods look similar meaning that all the three coverage to the identical optimum

ISSN: 2582-418X (online) 
Journal of Information Technology and Digital World (2020)

Vol.02/ No. 01

Pages: 43-52

https://www.irojournals.com/itdw/

DOI: https://doi.org/10.36548/jitdw.2020.1.004

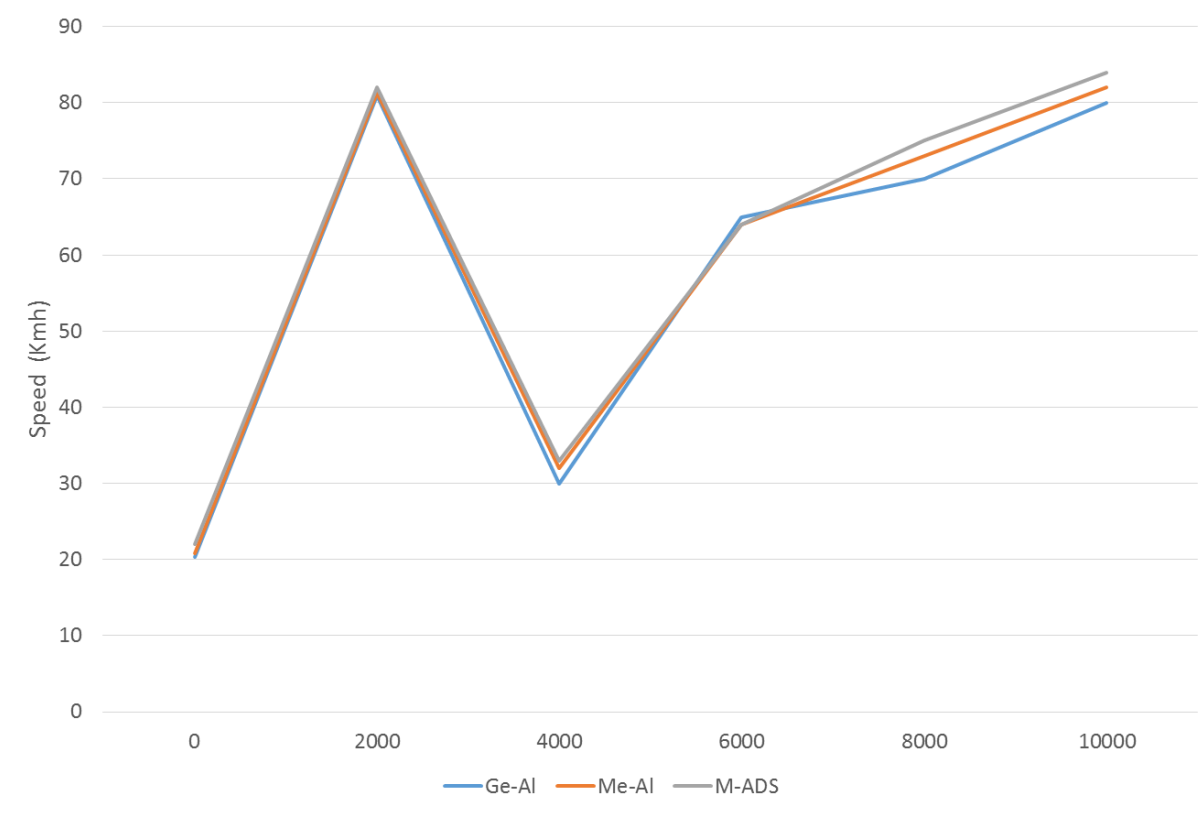

Figure.4 Performance of Metaheuristic Optimization

\section{Conclusion}

The paper presents the speed regulation of the self-driving vehicles by optimizing the gain parameters of the proportional, derivation and the integral components of the PID controller with the integral errors as the cost function. The optimization was achieved employing three different metaheuristics $\mathrm{Ge}-\mathrm{Al}, \mathrm{Me}-\mathrm{Al}$ and M-ADS and the results evaluation proved that all the three methods converged at the optimum and delivered similar performance compared to the conventional optimization techniques that were employed in adjusting the absolute error that is integral and the minimizing oscillatory performances and the performance index.

\section{References}

[1] Moscato, Pablo. "On evolution, search, optimization, genetic algorithms and martial arts: Towards memetic algorithms." Caltech concurrent computation program, C3P Report 826 (1989): 1989.

ISSN: 2582-418X (online) 
Journal of Information Technology and Digital World (2020)

Vol.02/ No. 01

Pages: 43-52

https://www.irojournals.com/itdw/

DOI: https://doi.org/10.36548/jitdw.2020.1.004

[2] Killingsworth, N., and Miroslav Krstic. PID tuning using extremum seeking. No. UCRL-JRNL-217161. Lawrence Livermore National Lab.(LLNL), Livermore, CA (United States), 2005.

[3] Audet, Charles, and John E. Dennis Jr. "Mesh adaptive direct search algorithms for constrained optimization." SIAM Journal on optimization 17, no. 1 (2006): 188-217.

[4] Smys, S., Jennifer S. Raj, and Nixon Augustine. "Autonoumous Vehicle Navigation in Communication Challenged Environments-A Simulation Approach." (2011).

[5] Ghaheri, Ali, Saeed Shoar, Mohammad Naderan, and Sayed Shahabuddin Hoseini. "The applications of genetic algorithms in medicine." Oman medical journal 30, no. 6 (2015): 406.

[6] Rout, M. K., D. Sain, S. K. Swain, and S. K. Mishra. "PID controller design for cruise control system using genetic algorithm." In 2016 International Conference on Electrical, Electronics, and Optimization Techniques (ICEEOT), pp. 4170-4174. IEEE, 2016.

[7] Ribeiro, Jussara MS, Murillo F. Santos, M. J. Carmo, and M. F. Silva. "Comparison of PID controller tuning methods: analytical/classical techniques versus optimization algorithms." In 2017 18th international Carpathian control conference (ICCC), pp. 533-538. IEEE, 2017.

[8] Metawa, Noura, M. Kabir Hassan, and Mohamed Elhoseny. "Genetic algorithm based model for optimizing bank lending decisions." Expert Systems with Applications 80 (2017): 75-82.

[9] Aparicio, Francisco, Felipe Jiménez, and Javier Sánchez. "Development and use of vehicle dynamics simulation software as support for road vehicles theory teaching." Computer Applications in Engineering Education 17, no. 4 (2009): 467-478.

[10] Smys, S., and G. Ranganathan. "Robot assisted sensing, control and manufacture in automobile industry." J ISMAC 1, no. 03 (2019): 180-187.

[11] Ramesh, S., and S. Smys. "A software-based heuristic clustered (sbhc) architecture for the performance improvement in manet." Wireless Personal Communications 97, no. 4 (2017): 6343-6355.

[12] Manoharan, Samuel. "An Improved Safety Algorithm for Artificial Intelligence Enabled Processors in Self Driving Cars." Journal of Artificial Intelligence 1, no. 02 (2019): 95-104.

ISSN: 2582-418X (online) 